\title{
DÜBLIN
}

Technological University Dublin

ARROW@TU Dublin

\section{Improving enzymatic hydrolysis of brewer spent grain with nonthermal plasma}

\author{
Rajeev Ravindran \\ Technological University Dublin, rajeev.ravindran@tudublin.ie \\ Chaitanya Sarangapani \\ Technological University Dublin, chaitanyakrishna.sarangapani@tudublin.ie \\ Swarna Jaiswal \\ Technological University Dublin, swarna.jaiswal@tudublin.ie
}

See next page for additional authors

Follow this and additional works at: https://arrow.tudublin.ie/schfsehart

Part of the Food Biotechnology Commons, Molecular, Genetic, and Biochemical Nutrition Commons, and the Other Medicine and Health Sciences Commons

\section{Recommended Citation}

Rajeev Ravindran, Chaitanya Sarangapani, Swarna Jaiswal, Peng Lu, P.J. Cullen, Paula Bourke, Amit K. Jaiswal, Improving enzymatic hydrolysis of brewer spent grain with nonthermal plasma, Bioresource Technology, Volume 282, 2019, Pages 520-524, ISSN 0960-8524, DOI: 10.1016/j.biortech.2019.03.071.

This Article is brought to you for free and open access by the School of Food Science and Environmental Health at ARROW@TU Dublin. It has been accepted for inclusion in Articles by an authorized administrator of ARROW@TU Dublin. For more information, please contact arrow.admin@tudublin.ie, aisling.coyne@tudublin.ie, gerard.connolly@tudublin.ie.

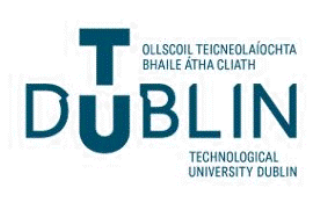




\section{Authors}

Rajeev Ravindran, Chaitanya Sarangapani, Swarna Jaiswal, Peng Lu, Patrick Cullen, Paula Bourke, and Amit Jaiswal 


\section{Improving enzymatic hydrolysis of brewer spent grain with nonthermal plasma}

2

3 Rajeev Ravindran ${ }^{a}$, Chaitanya Sarangapani ${ }^{a}$, Swarna Jaiswal ${ }^{\text {b }}$, Peng Lu ${ }^{a}$, P. J. Cullen ${ }^{c}$, 4 Paula Bourke ${ }^{\mathrm{a}}$, Amit K. Jaiswal ${ }^{\mathrm{a}}$ *

5

$6{ }^{a}$ School of Food Science and Environmental Health, College of Sciences and Health, 7 Technological University Dublin, City Campus, Cathal Brugha Street, Dublin D01 HV58, 8 Ireland.

$9{ }^{b}$ Centre for Research in Engineering and Surface Technology (CREST), FOCAS Institute,

10 Technological University Dublin, City Campus, Kevin Street, Dublin D08 NF82, Ireland.

$11{ }^{c}$ School of Chemical and Biomolecular Engineering, University of Sydney, Sydney, Australia

*Corresponding author

16 Email: amit.jaiswal@dit.ie; akjaiswal@outlook.com

17 Tel: +353 14024547

18

19

20 


\section{Abstract}

26 In this study, a new pre-treatment method based on novel non-thermal plasma technology was developed to improve the enzymatic hydrolysis of brewer's spent grain (BSG) and subsequent bioethanol production. A submerged dielectric barrier discharge plasma reactor system was applied for this purpose. Pre-treatments were performed by taking into account

30 variables including; voltages $(22 \mathrm{kV}, 25 \mathrm{kV}$ and $28 \mathrm{kV})$, solvent (acid, alkali and water) and time $(5,10,15 \mathrm{~min})$. The resulting treated biomass was subjected to enzymatic hydrolysis. A 2.14-fold increase in yield of the reducing sugar was achieved post hydrolysis when the biomass was treated in water for $10 \mathrm{~min}$ at a voltage setting of $28 \mathrm{kV}(162.90 \mathrm{mg} / \mathrm{g}$ of BSG) compared to control $(75.94 \mathrm{mg} / \mathrm{g}$ of $\mathrm{BSG})$. This research suggests that subjecting lignocellulose to plasma discharges can enhance the efficiency of enzymatic hydrolysis. A high ethanol titre was also obtained upon fermentation of the hydrolysate (25.062 $\mathrm{g} / \mathrm{l})$.

Keywords: Lignocellulose; biomass pretreatment; brewer's spent grain; atmospheric plasma, bioethanol production 


\section{Introduction}

49 Brewers spent grain (BSG) is a by-product of the brewing industry that is high in 50 polysaccharide, protein and lipid content (Mussatto et al., 2006). The global average production of brewers spent grain in 2016 was 39 million tonnes with the European union alone contributing 3.4 million tonnes (Lynch et al., 2016). Most of the spent grain generated in breweries end up being utilised as animal feed, compost, fertiliser or sent to landfill. BSG

54 is rich in cellulose and hemicellulose content which can be exploited to extract 5-C and 6-C fermentable sugars. Due to the highly recalcitrant nature of the biomass, BSG needs to be subjected to pre-treatment measures for the efficient extraction of sugars (Ravindran et al., 2018).

Pre-treatments are disruptive techniques that aim to expose the polysaccharide fraction of lignocellulose for enzymatic or microbial digestion (Hassan et al., 2018). Pre-treatment using atmospheric plasma potentially offers a non-toxic and sustainable method for the effective removal of recalcitrance from lignocellulose and other by-products. Several studies have investigated the effectiveness of plasma as a lignocellulose pre-treatment strategy for subsequent valorisation. For example, Schultz-Jensen et al. (2011) investigated the

64 effectiveness of plasma for subsequent bioethanol production from wheat straw. They reported the extent of lignin removal by plasma with respect to time. Baltazar-y-Jimenez et al., (2008) studied the changes in cellulose fibres exposed to atmospheric air plasma

67 treatment.

This study focusses on the effectiveness of atmospheric air plasma as a pre-treatment strategy

69 for BSG. The experiment was designed to include a liquid-based treatment strategy involving 70 acid, alkali and water. The pre-treated biomass was then subjected to enzymatic hydrolysis 71 followed by bioethanol production. 


\section{Materials and methods}

73

74

\subsection{Feedstock}

Brewers' spent grain (BSG) was supplied by a local brewery (Dublin, Ireland). The material was weighed and then dried in a hot air oven at $60^{\circ} \mathrm{C}$ for $48 \mathrm{~h}$. The dried BSG was then ground and sieved through a $350 \mu \mathrm{m}$ mesh to obtain a relatively uniform particle size. The size-reduced biomass was stored in a cool and dry place for further experiments. All chemicals such as $\mathrm{NaOH}$, sulphuric acid and saccharifying enzymes such cellulase and hemicellulase were purchased from Sigma Aldrich.

\subsection{Component analysis}

The compositional variations in BSG before and after pre-treatment was analysed by using the NREL protocol. As a control measure the composition of native BSG was also determined. Biomass was hydrolysed by mixing it with $72 \% \mathrm{H}_{2} \mathrm{SO}_{4}$ for $1 \mathrm{~h}$ at $30^{\circ} \mathrm{C}$. The acid concentration was then diluted to $4 \%$ with deionised water and autoclaved at $121^{\circ} \mathrm{C}$ for $1 \mathrm{~h}$.

The solid fractions were then separated from the liquids and dried at $80^{\circ} \mathrm{C}$ for $48 \mathrm{~h}$ following which the acid insoluble lignin was determined. The liquid obtained was used to measure the acid soluble lignin by measuring the absorbance at $205 \mathrm{~nm}$. The individual sugars present in the hydrolysate were identified and quantified by HPLC (Rezex ROA H${ }^{+}$, Waters e2695 Separation module, RI) (Sluiter et al., 2008).

\subsection{Pre-treatment of BSG using atmospheric air pressure plasma}

Pre-treatment of BSG was performed in a submerged dielectric barrier discharge (DBD) plasma reactor. Fig. 1 shows the schematics of the submerged DBD plasma reactor. The DBD plasma source employs a conventionally coaxial electrode configuration. The high voltage electrode is sealed in a quartz tube. The DBD tube and the ground electrode are submerged into the treated liquids so that the liquid serves as both an additional dielectric 
96 barrier layer and the coolant for the discharge. Consequently, the plasma column length is 97 determined by the depth of the DBD tube within the liquid. The thickness of both inner and outer quartz barrier was $2 \mathrm{~mm}$ and the discharge gap between the two coaxial quartz tubes was also $2 \mathrm{~mm}$. In this study, the liquid suspension was treated in a cylindrical acrylic tank

100 with a total volume of $300 \mathrm{ml}$. Air was used as the plasma working gas and its flow rate 101 controlled by a mass flow controller (KOFLOC DF300C). In this study, the air flow rate was 102 fixed at 1SLM. The post-discharge afterglow plasma effluent is bubbled into the liquid 103 through four gas diffusers which are attached at the end of the tube. The plasma discharge is 104 driven by a high voltage (HV) AC power supply (PVM500, Information Unlimited). The pre105 treatment experiment was designed to determine the voltage and reaction time that best suited 106 recalcitrance removal from BSG while collaborating with the nature of the solvent. 107 Therefore, three voltage (peak-to-peak value) settings viz. $22 \mathrm{kV}, 25 \mathrm{kV}$ and $28 \mathrm{kV}$ were tested for different duration settings (5, 10 and $15 \mathrm{~min})$.

\subsection{Enzymatic hydrolysis}

110 The enzymatic hydrolysis of BSG was performed based on previous work conducted in our

111 lab (Ravindran et al., 2018). The hydrolysates were then collected by centrifugation of the

112 reaction mixture at $10000 \mathrm{rpm}$ for $15 \mathrm{~min}$ followed by reducing sugar content estimation

113 following dinitrosalicylic acid assay. Enzymatic digestibility was measured by calculating the 114 hexoses yield (\% cellulose) released from hydrolysis after pretreatment. The enzymatic 115 digestibility was calculated by methods described by Zhang et al., 2007.

\section{$1162.5 \quad$ Individual sugar, inhibitor and organic acid analysis}

117 Detection and quantification of monosaccharides and any organic acids formed was 118 performed using an Allaince HPLC (Waters, e2695 Separation module) with a Rezex ROA119 Organic acid H+ (8\%) column, (350 x $7.8 \mathrm{~mm}$; Phenomenex, UK) equipped with RI detector. 
120 The HPLC system was also equipped with an autosampler, degasser and isocratic pump. The

121 HPLC was operated in isocratic mode using $\mathrm{H}_{2} \mathrm{SO}_{4}(0.005 \mathrm{M})$ as the mobile phase. Samples

122 were analysed at $65^{\circ} \mathrm{C}$ maintaining a flow rate of $0.6 \mathrm{ml} / \mathrm{min}$. An isocratic mobile phase of

$1230.01 \mathrm{M}$ sulphuric acid was used to detect and estimate the number of inhibitors such as

124 furfural and hydroxymethyl furfural in the hydrolysate.

\section{$125 \quad 2.6 \quad$ Bioethanol production}

126 The sugar rich hydrolysate obtained after enzymatic hydrolysis was filtered to remove any 127 particulate matter and supplemented with $0.1 \%$ yeast extract and $0.1 \%$ peptone. The reaction 128 mixture was autoclaved and then subjected to fermentation to produce bioethanol. 129 Fermentation was carried out in $250 \mathrm{ml}$ conical flasks with a total reaction volume of $100 \mathrm{ml}$.

$1301 \mathrm{ml}$ of Saccharomyces cerevisiae inoculum $\left(2.7 \times 10^{8}\right.$ cells $\left./ \mathrm{ml}\right)$ was added to the reaction 131 mixture. The fermentation reaction was conducted at $30^{\circ} \mathrm{C}$ for $72 \mathrm{~h}$. After fermentation the 132 reaction mixture was centrifuged and filtered using $0.4 \mu$ filters and the ethanol produced was 133 estimated by using Gas Chromatography. The injector temperature was set at $220^{\circ} \mathrm{C}$ while 134 the column oven was set at an initial temperature of $80^{\circ} \mathrm{C}$ and ramped up to $160^{\circ} \mathrm{C}$ at a rate of $13540^{\circ} \mathrm{C}$ per min and held for 7 minutes. A flame ionisation detector was used for analysing the 136 ethanol content and was set at a temperature of $200^{\circ} \mathrm{C}$.

\section{$137 \quad 2.7 \quad$ Characterisation of pre-treated BSG}

\section{$138 \quad 2.7 .1 \quad$ FTIR analysis}

139 Any induced chemical changes of the functional groups of the different components in BSG

140 by plasma treatment was studied using FTIR spectroscopy. Untreated BSG was used as the 141 control to compare the differences. A Perkin Elmer Spectrum GX FT-IR (UATR) microscope 142 (USA) was employed for this study. The FTIR spectra for the BSG samples were recorded 143 from 4000 to $400 \mathrm{~cm}^{-1}$ with 16 scans at a resolution of $0.3 \mathrm{~cm}^{-1}$ in transmission mode. 


\subsubsection{Thermal Behaviour}

145 Any induced differences in the thermal behaviour of BSG after pre-treatment was studied 146 using differential scanning calorimetry (DSC). $55 \mathrm{mg}$ of the pretreated BSG was placed in an 147 aluminium pan with an empty pan used as a reference. All measurements were carried out 148 between $25^{\circ} \mathrm{C}$ and $500^{\circ} \mathrm{C}$ with a linear increase of $10^{\circ} \mathrm{C}$ in a Shimadzu DSC-60 installed with 149 TA-60WS software.

\section{Results and discussion}

\section{$151 \quad 3.1 \quad$ Effect of pre-treatment on the composition of brewer's spent grain}

152 Untreated BSG was subjected to composition analysis to determine the nature of the 153 polysaccharides as well as recalcitrant materials present. Glucose was found to be the 154 predominant sugar in the BSG samples followed by xylose. This makes BSG a good substrate for biofuel production following saccharification strategies. The glucose content arising from the cellulose fraction of native BSG was found to be $19.21 \pm 0.3 \mathrm{~g} / 100 \mathrm{~g}$ of BSG. Xylose was found to be the second most abundant sugar in BSG contributing to $\sim 63 \%$ of the total hemicellulose content $(26.94 \pm 0.6 \mathrm{~g} / 100 \mathrm{~g})$. BSG was also rich in lignin with the total lignin content amounting to $30.48 \pm 2.1 \mathrm{~g} / 100 \mathrm{~g}$. These findings were in agreement with the

160 composition of BSG reported by studies reported elsewhere (Ikram et al., 2017). Several studies have reported the conversion of glucose and xylose into fuel alternatives such as ethanol and butanol (Das et al., 2013).

163 Atmospheric pressure plasma are sources of highly reactive species such as ozone, hydroxyl

164 ions, hydronium ions etc. These species react with chemical structures in their vicinity to 165 effectively disintegrate the constituent chemicals. The ozone molecule, typically generated in 166 abundance in air plasmas, has the capacity to specifically attack lignin while leaving the 167 cellulose and hemicellulose intact. Characterisation of the pretreated BSG revealed that the 
168 total lignin content was reduced to $19.50 \pm 0.5 \mathrm{~g} / 100 \mathrm{~g}$ of BSG. An increase in cellulose 169 registering of $28.13 \pm 0.9 \mathrm{~g} / 100 \mathrm{~g}$ of $\mathrm{BSG}$ was found while only a slight increase in

170 hemicellulose was observed $(27.55 \pm 0.3 \mathrm{~g} / 100 \mathrm{~g}$ of BSG). This might be due to the inherent

171 crystalline nature of cellulose to resist chemical attacks. Meanwhile, hemicellulose is 172 amorphous in nature can deteriorate more readily in the presence of reactive species

173 (Chundawat et al., 2010).

174 Several studies have been published focusing on the utilisation of BSG for the production of value-added products. For example, in a recent study Liguori et al., 2018 achieved $75 \mathrm{~g} / \mathrm{l}$ of reducing sugar on subjecting BSG to enzymatic hydrolysis. This study involved the use of concentrated alkali to digest the lignin fibres. The alkaline treatment was preceded by

178 hemicellulose removal using sulfuric acid. A thermomechanical pretreatment was devised for 179 BSG by Pierre et al., (2011) where a D.I.C (in French: Détente Instantanée Contrôlée) reactor was used. Employing a range of processing pressures the researchers was able to obtain a maximum glucose yield of $24 \mathrm{~g}$ per $100 \mathrm{~g}$ of BSG. An earlier study performed in our laboratory examined the effect of various pretreatments on the composition as well as enzymatic hydrolysis of BSG. The reducing sugar yielded from novel dielectric barrier discharge plasma was comparable with the figures obtained for different pretreatment strategies (Ravindran et al 2018).

\subsection{Effect of different solvents on plasma pre-treatment of BSG}

187 Table1 presents the results obtained in the study. All the pre-treatment parameters tested were

188 effective in yielding higher reducing sugar compared to control. The results show that plasma

189 pre-treatment of lignocellulosic biomass in either acid, neutral or alkaline conditions can

190 result in considerable removal of recalcitrance. However, the application under alkali

191 conditions resulted in excessive foaming and spilling of the liquor especially in the case of 
192 higher voltage levels and longer duration treatments. This restricted the inclusion of higher 193 voltages and longer treatment times. On the other hand, a higher reducing sugar yield was

194 obtained for all settings of voltage level and treatment times when water was used as the pre195 treatment solvent. This can be attributed to the increases in the concentration of reactive

196 species generated. The initial $\mathrm{pH}$ of the solution exposed to plasma plays an important role in 197 the degradation process. In addition to the aforementioned species, UV light and shock waves 198 may also cause breakdown of the lignocellulose matrix (Bruggeman et al., 2007). A low pH 199 environment leads to reduced efficiency of the plasma induced degradation (Su et al., 2002). 200 At a $\mathrm{pH}$ range of $6.5-8.5, \mathrm{O}_{3}$ and $\mathrm{OH}$ radicals predominate the disintegration process for the 201 lignocellulosic matrix. The oxidative capacity of $\mathrm{O}_{3}$ disrupts the $-\mathrm{C}=\mathrm{C}-$ bonds present in 202 the aromatic rings (Grabowski et al., 2007). The abundance of this kind of bond may be cited 203 as the reason to why pre-treatment techniques specifically decompose this type of polymer.

204 However, at a higher $\mathrm{pH}$ of $>8.5$ the presence of $\mathrm{OH}_{2}^{-}$can scavenge ${ }^{\circ} \mathrm{OH}$ radicals, 205 decreasing the efficiency of the pre-treatment process. The findings of an extensive study on 206 the effect of $\mathrm{pH}$ on the efficiency of atmospheric air plasma treatment performed in our lab 207 can be found here (Sarangapani et al., 2018). The maximum reducing sugar yield was 208 obtained when water was used as the pre-treatment solvent and treatment was performed maintaining a voltage of $28 \mathrm{kV}$ for $10 \mathrm{~min}(162.9 \pm 0.5 \mathrm{mg} / \mathrm{g}$ of $\mathrm{BSG})$. Additionally, the enzymatic digestibility was determined to be $86.8 \%$. This was possibly because of the

211 extensive damage incurred by the polysaccharide fraction along with lignin which left less

212 cellulose and hemicellulose for enzymatic degradation.

\section{$213 \quad 3.3 \quad$ Inhibitors in pre-treatment liquor}

214 The pre-treatment liquor was subjected to HPLC analysis and was found to be have trace 215 amounts of individual sugars such as glucose, galactose and mannose. Interestingly, small 216 amounts of organic acids viz. citric acid and oxalic acids were also found. Schultz-Jensen et 
217 al. (2011), in an extensive study involving plasma treatment of wheat straw reported the

218 formation of a spectrum of organic acids. However, no furfural or HMF formation was

219 observed.

\subsection{FTIR and DSC profiles of untreated and pre-treated brewer's spent grain}

221 Fourier Transform Infrared Spectroscopy is a simple qualitative analytical technique that

222 indicates compositional changes in the biomass based on prominence, presence or absence of

223 functional groups pertaining to each individual component (cellulose, hemicellulose and

224 lignin). Diminishing of respective peaks indicates change in the inherent structure due to

225 bond breakage. For example, the glycosidic linkages between cellulose and hemicellulose is

226 represented by a peak at $895 \mathrm{~cm}^{-1}$. The intensity of this peak was lower in the plasma treated

227 BSG compared to the native counterpart indicating bond breakage. The peak at $1247 \mathrm{~cm}^{-1}$

228 which represents aryl-alkyl ether bonds (C-O-C) was also less prominent in the pretreated

229 BSG. There was stark reduction of the peak at $1526 \mathrm{~cm}^{-1}$ which represents $\mathrm{C}=\mathrm{C}$ bonds in the

230 aromatic ring of lignin for the plasma treated biomass. This agreed with the changes in the

231 composition of pretreated BSG. The breakage of ester and carboxylic bonds in the

232 hemicellulose was recognizable in the FTIR spectrum with a diminished band at $1739 \mathrm{~cm}^{-1}$

233 for the BSG exposed to plasma. The pre-treatment however did not result in high degrees of

234 demethylation of lignocellulose which was observable by bands at $2920 \mathrm{~cm}^{-1}$ for both native

235 and treated BSG. Furthermore, the absence of bands in the $3000-3500 \mathrm{~cm}^{-1}$ range is indicative

236 of stretching of $-\mathrm{OH}$ groups in the pretreated BSG (Santos et al., 2015).

237 Differential Scanning Calorimetry (DSC) was performed to study any changes brought about

238 by plasma in the physical properties of BSG. The thermogram for native BSG was devoid of

239 any glass transition. The crystallisation event occurred between $26^{\circ} \mathrm{C}$ and $309.9^{\circ} \mathrm{C}$.

240 Vaporisation of water and changes in the crystalline nature of the sample may have 
241 contributed to this event. This was followed by melting. The melting temperature was found

242 to be $361.05^{\circ} \mathrm{C}$. The effect of plasma on the physical properties of BSG was evident as there

243 were stark differences between the thermograms of the pretreated and native BSG. The DSC

244 thermogram for plasma treated BSG showed distinct peaks that suggested an event for

245 crystallisation from $28.49^{\circ} \mathrm{C}$ to $279.11^{\circ} \mathrm{C}$. This was followed by a short melting and then

246 ending transient. The melting temperature was recorded at $296^{\circ} \mathrm{C}$.

\section{$247 \quad 3.5 \quad$ Bioethanol production using plasma treated BSG}

248 The hydrolysate obtained after enzymatic digestion of the plasma pretreated BSG was subjected to fermentation for the production of bioethanol. S. cerevisiae was employed as the ethanol producer. A maximum ethanol titre of $25.062 \mathrm{~g} / \mathrm{l}$ of ethanol was obtained after fermentation for $72 \mathrm{~h}$. On the other hand, the bioethanol production using the control sample yielded $11.231 \mathrm{~g} / \mathrm{l}$ of ethanol. The ethanol titre obtained in this study is comparable to ethanol yields reported elsewhere. For example, Srinorakutara et al. (2014) reported an ethanol titre of $30.40 \mathrm{~g} / \mathrm{l}$ employing optimised fermentation methods using acid pretreated sugar cane trash. The ethanol yield obtained from the fermentation of lignocellulose-derived sugars can depend on process optimisation as well as the nature of ethanol producers used. On calculating the yield, $1 \mathrm{~g}$ of reducing sugar yielded $0.16 \mathrm{~g}$ of ethanol. A low theoretical yield may have been contributed by the abundance of xylose in the hydrolysate which remained unutilised due to the absence of a pentose-fermenting microbe. A synergistic combination of microbial species that can ferment 5-C and 6-C sugars can result in higher ethanol titre (Das et al., 2014).

\section{Conclusion}

264 In our study, atmospheric plasma in solvents was an effective pre-treatment strategy to reduce recalcitrance from BSG. There was $36 \%$ decrease in the total lignin content of pretreated 
BSG using a water solvent. This resulted in a higher reducing sugar yield following enzymatic hydrolysis registering a 2.14-fold increase. There were no toxic inhibitors found following the treatment although trace amounts of organic acids were detected. This may have contributed to the higher ethanol titre following fermentation. This technology offers a promising method to achieve recalcitrance removal from lignocellulose.

\section{Acknowledgements}

The authors would like to acknowledge the funding from Technological University Dublin

(Formally Dublin Institute of Technology) under the Fiosraigh Scholarship programme, 2014.

This work has also emanated from research supported in part by a research grant from

Science Foundation Ireland (SFI) under the Grant Number SFI/16/BBSRC/3391 and the

BBSRC under the Grant Reference BB/P008496/ and Science Foundation Ireland (SFI) under

Grant Number 14/IA/2626 and the Food Institutional Research Measure (FIRM) administered

by Department of Agriculture, Food and the Marine, Ireland (DAFM 13/F/442).

\section{References}

282 1. Baltazar-y-Jimenez, A., Bistritz, M., Schulz, E., Bismarck, A. 2008. Atmospheric air pressure plasma treatment of lignocellulosic fibres: Impact on mechanical properties and adhesion to cellulose acetate butyrate. Composites Sci. Technol. 68(1), 215-227. breakdown in a metal pin-water electrode system. J. Phys. D: Appl. Phys. 40(16), 4779.

3. Chundawat, S.P.S., Vismeh, R., Sharma, L.N., Humpula, J.F., da Costa Sousa, L.,

Chambliss, C.K., Jones, A.D., Balan, V., Dale, B.E. 2010. Multifaceted 
characterization of cell wall decomposition products formed during ammonia fiber expansion (AFEX) and dilute acid based pretreatments. Bioresour. Technol. 101(21), 8429-8438.

4. Das, S.P., Ravindran, R., Deka, D., Jawed, M., Das, D., Goyal, A. 2013. Bioethanol production from leafy biomass of mango (Mangifera indica) involving naturally isolated and recombinant enzymes. Prep. Biochem. Biotechnol. 43(7), 717-734.

5. Das, S.P., Ravindran, R., Ghosh, A., Deka, D., Das, D., Jawed, M., Fontes, C.M., Goyal, A. 2014. Efficient pretreatment for bioethanol production from water hyacinth (Eichhornia crassipes) involving naturally isolated and recombinant enzymes and its recovery. Environ. Prog. Sustain. Energy. 33(4), 1396-1404.

6. Grabowski, L., Van Veldhuizen, E., Pemen, A., Rutgers, W. 2007. Breakdown of 302 Technol. 16(2), 226.

7. Hassan, S. S., Williams, G. A., \& Jaiswal, A. K., 2018. Emerging technologies for the pretreatment of lignocellulosic biomass. Bioresour. Technol. 262, 310-318

8. Ikram, S., Huang, L., Zhang, H., Wang, J., Yin, M. 2017. Composition and Nutrient Value Proposition of Brewers Spent Grain. J. Food Sci. 82(10), 2232-2242.

9. Kerby, C., Vriesekoop, F. 2017. An overview of the utilisation of brewery byproducts as generated by British craft breweries. Beverages, 3(2), 24.

10. Liguori, R., Soccol, C., Porto de Souza Vandenberghe, L., Woiciechowski, A., \& Faraco, V. 2015. Second generation ethanol production from brewers' spent grain. Energies, 8, 2575-2586.

11. Mussatto, S. I., \& Roberto, I. C., 2006. Chemical characterization and liberation of pentose sugars from brewer's spent grain. J. Chem. Technol. Biotechnol.: Int. Res. Process, Environ. Clean Technol. 81(3), 268-274. 
12. Mussatto, S., Dragone, G., Roberto, I. 2006. Brewers' spent grain: generation, characteristics and potential applications. J. Cereal Sci. 43(1), 1-14.

13. Ravindran, R., Jaiswal, S., Abu-Ghannam, N., Jaiswal, A.K. 2018. A comparative analysis of pretreatment strategies on the properties and hydrolysis of brewers' spent grain. Bioresour. Technol. 248, 272-279.

14. Santos, D.M.d., Bukzem, A.d.L., Ascheri, D.P.R., Signini, R., Aquino, G.L.B.d. 2015. Microwave-assisted carboxymethylation of cellulose extracted from brewer's spent grain. Carbohydr. Polymer. 131, 125-133.

15. Sarangapani, C., Lu, P., Behan, P., Bourke, P., Cullen, P.J. 2018. Humic acid and trihalomethane breakdown with potential by-product formations for atmospheric air plasma water treatment. J. Indust. Eng. Chem. 59, 350-361.

16. Schultz-Jensen, N., Kádár, Z., Thomsen, A.B., Bindslev, H., Leipold, F. 2011. Plasma-assisted pretreatment of wheat straw for ethanol production. Appl. Biochem. Biotechnol. 165(3-4), 1010-1023.

17. Srinorakutara, T., Suttikul, S., Butivate, E., Panphan, V., Boonvitthya, N. 2014. Optimization on pretreatment and enzymatic hydrolysis of sugarcane trash for ethanol production. J. Food Sci. Eng. 4(3), 148-154.

18. Su, Z.-Z., Ito, K., Takashima, K., Katsura, S., Onda, K., Mizuno, A. 2002. OH radical generation by atmospheric pressure pulsed discharge plasma and its quantitative analysis by monitoring CO oxidation. J. Phys. D, 35(24), 3192.

19. Zhang, Y. H. P., Schell, D. J., McMillan, J. D. 2000. Methodological analysis for determination of enzymatic digestibility of cellulosic materials. Biotechnol. Bioeng, 96 $1,188-194$. 


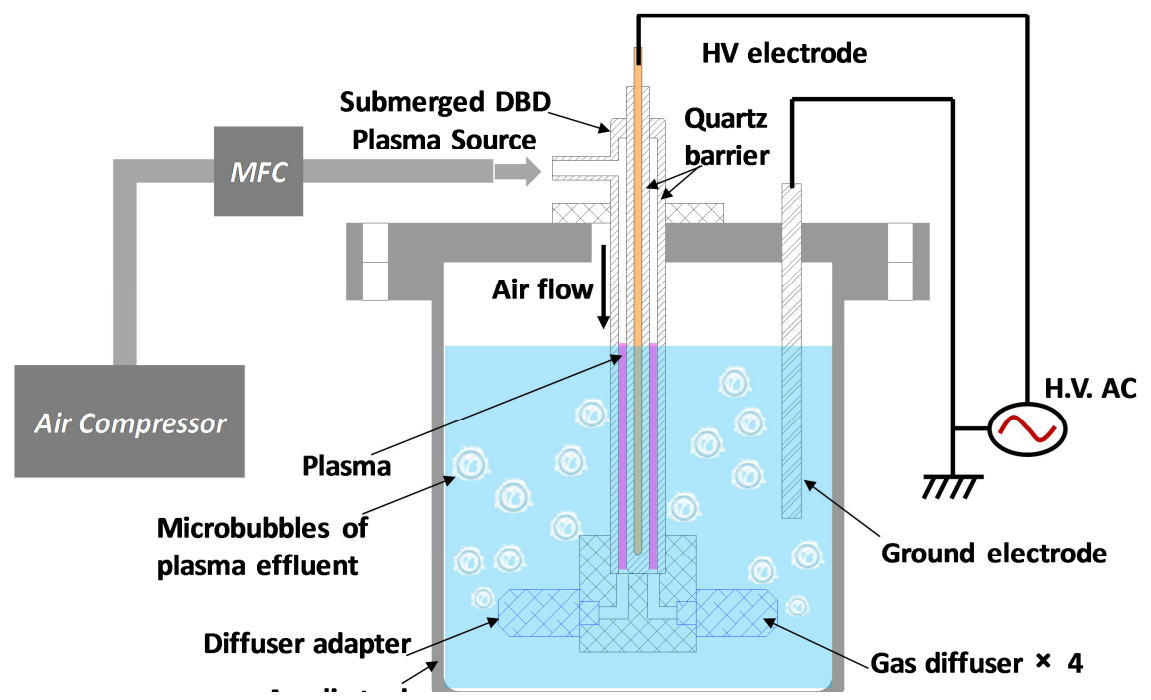

Fig. 1. Schematic of atmospheric pressure plasma reactor

Table 1. Reducing sugar yield obtained after enzymatic hydrolysis of each experimental trail

\begin{tabular}{ccccc}
\hline S. no & $\begin{array}{l}\text { Voltage } \\
(\mathrm{kV})\end{array}$ & $\begin{array}{c}\text { Time } \\
(\mathrm{min})\end{array}$ & Solvent & $\begin{array}{l}\text { Reducing sugar } \\
(\mathrm{mg} / \mathrm{ml})\end{array}$ \\
\hline 1 & 22 & 5 & Water & $154.18 \pm 1.2$ \\
2 & 22 & 10 & Acid & $123.95 \pm 0.3$ \\
3 & 22 & 15 & Alkali & $130.18 \pm 2.1$ \\
4 & 25 & 5 & Acid & $129.25 \pm 0.7$ \\
5 & 25 & 10 & Alkali & $135.04 \pm 1.3$ \\
6 & 25 & 15 & Water & $148.55 \pm 0.4$ \\
7 & 28 & 5 & Alkali & $149.48 \pm 0.2$ \\
8 & 28 & 10 & Water & $162.9 \pm 0.5$ \\
9 & 28 & 15 & Acid & $137.66 \pm 1.9$ \\
10 & Control & - & - & $75.94 \pm 0.1$ \\
\hline
\end{tabular}


